\title{
High azithromycin concentration in lungs by way of bovine serum albumin microspheres as targeted drug delivery: lung targeting efficiency in albino mice
}

Balakeshwa Ramaiah ${ }^{1 *}$, Sree Harsha Nagaraja², Usha Ganganahalli Kapanigowda ${ }^{3}$, Prakash Rao Boggarapu ${ }^{3}$ and Rajarajan Subramanian ${ }^{1}$

\begin{abstract}
Background: Following administration, the antibiotic travels freely through the body and also accumulates in other parts apart from the infection site. High dosage and repeated ingestion of antibiotics in the treatment of pneumonia leads to undesirable effects and inappropriate disposition of the drug. By way of targeted lung delivery, this study was intended to eliminate inappropriate azithromycin disposition and to achieve higher azithromycin concentration to treat deeper airway infections.

Methods: The Azithromycin Albumin Microspheres (AAM) was prepared by emulsion polymerization technique. The optimized AAM was subjected to in vitro release study, release kinetics, XRD and stability studies. Further, in vivo pharmacokinetics and tissue distribution of azithromycin released from AAM and azithromycin solution in albino mice was investigated to prove suitability of moving forward the next steps in the clinic.

Results: The mean particle size of the optimized AAM was $10.02 \mu \mathrm{m}$, an optimal size to get deposited in the lungs by mechanical entrapment. The maximum encapsulation efficiency of $82.3 \%$ was observed in this study. The release kinetic was significant and best fitted for Korsmeyer-Peppas model $\left(R^{2}=0.9962, n=0.41\right)$. The XRD and stability study showed favorable results. Azithromycin concentration in mice lungs ( $40.62 \mathrm{\mu g} \mathrm{g}^{-1}, 30 \mathrm{~min}$ ) of AAM was appreciably higher than other tissues and plasma. In comparison with control, azithromycin concentration in lungs was $30.15 \mathrm{\mu g} \mathrm{g}^{-1}$ after $30 \mathrm{~min}$. The azithromycin AUC (929.94 $\left.\mu \mathrm{g} \mathrm{h} \mathrm{mL}^{-1}\right)$ and intake rate $\left(\mathrm{r}_{\mathrm{e}}\right)$ (8.88) for lung were higher and statistically significant in AAM group. Compared with spleen and liver, the targeting efficacy $\left(t_{e}\right)$ in mice lung increased by a factor of 40.15 and $\sim 14.10$ respectively. Subsequently by a factor of 8.94 , the ratio of peak concentration $\left(C_{e}\right)$ in lung was higher in AAM treated mice. The AAM lung tissue histopathology did not show any degenerative changes.
\end{abstract}

Conclusions: High azithromycin concentration in albino mice lung was adequately achieved by targeted drug delivery.

Keywords: Azithromycin, Albumin microspheres, Sigma plot, Targeting efficacy, Lung targeting

\footnotetext{
* Correspondence: balupharmacy@gmail.com

1 Department of Pharmaceutics, Karnataka College of Pharmacy, \#33/2,

Tirumenahalli, Hegde Nagar Main Road, Bengaluru, Karnataka 560064, India

Full list of author information is available at the end of the article
} 


\section{Background}

Worldwide studies have revealed pneumonia to be the primary cause of death among children. Lung disorder generally affects 1 in 7 people and it is believed to be the major cause of death in the United States [1,2]. The antimicrobial therapy has considerably reduced the outbreak of pneumonia, but there are instances reported on the failure of antimicrobial therapy. This was primarily owing to the increased antimicrobial-resistant pathogenic microorganisms, which resulted in the administration of ineffective treatments [3]. Following administration, drug travels freely through the body and also accumulates in other parts apart from the infection site. High dosage and repeated ingestion of antibiotics in the treatment of pneumonia leads to undesirable effects and inappropriate disposition of the drug.

The sub-therapeutic antibiotic concentration at the infection site and prolong usage of antibiotic has led to antibiotic resistance [4]. These issues facilitate the requirement of a targeted drug delivery model to maximize the therapeutic efficacy against pneumonia. Drug targeting at the site of infection minimizes dosage of the drug required to achieve the optimum serum concentration leading to obtain the desired pharmacological action. The role of drug targeting was found to be evident considering various parameters such as pharmaceutical, biopharmaceutical, pharmacokinetic, pharmacodynamic and clinical [5]. Additionally, development of targeted drug for treatment of pneumonia improves health care and promises survival of the patient [1].

Azithromycin, (9-deoxo-9a-aza-9a-methyl-9a-homoerythromycin A) dihydrate, a macrolide antiobiotic used as a broad spectrum antibiotic was proved to be efficacious in the treatment of pneumonia. It is primarily active against Haemophilus influenza, Moraxella catarrhalis, Streptococcus pneumonia, Chlamydophila (Chlamydia) pneumonia and Mycoplasma pneumonia [6]. Azithromycin has high affinity towards the $50 \mathrm{~S}$ ribosomal subunit of the organism and blocks its protein synthesis. Several unique pharmacokinetic properties such as excellent tissue penetration, high volume of distribution and prolong half life has lead the use of azithromycin for the treatment of pneumonia. Azithromycin has very large volume of distribution $(2100 \mathrm{~L})$ results in good tissue penetration and a long half-life (40-60 h) [4]. The antimicrobial activity of azithromycin against pneumonia pathogens depends on its relative concentration at the infection site. Therefore increasing localized azithromycin tissue concentration will clear the pathogen more rapidly and reduce the possibility of drug resistance.

The tissue minimum inhibitory concentration $\left(\mathrm{MIC}_{90}\right)$ breakpoint of azithromycin susceptibility against major organisms in US citizens was found to be $\leq 4 \mu \mathrm{g} \mathrm{mL} \mathrm{m}^{-1}$ [6]. As though to support this theory, clinical studies [7, 8] showed the azithromycin coverage in lungs was high with extended release of single or double dose microspheres. The better dosage regimen has improved azithromycin concentration especially in lower respiratory tract. The only novel marketed azithromycin microsphere (Zmax in USA) had proven to increase the plasma concentration by two to threefold to that of the conventional preparations [4]. The antimicrobial and post antibiotic effect (PAE) of azithromycin are characterized as concentration dependent [9]. By drug targeting, azithromycin concentration at the site of infection will be higher when compared to serum [6]. On intravenous administration, microspheres with 7$15 \mu \mathrm{m}$ particle range are capable of being entrapped by lung capillaries [10].

In the recent past, a great deal of awareness has been observed in the preparation of microspheres using albumin for targeted drug delivery. The rationale was to specifically deliver the drug to the target tissues or cells by evading other tissue from undesirable effect [11]. A drastic increase, in the use of albumin in drug delivery was observed since 1970s proving albumin as a drug carrier and depicting greater attention in drug delivery system [12]. Albumin microspheres are nontoxic, physically and chemically stable, moreover they have specific receptor affinity in lungs. Albumin has numerous binding sites for exogenous ligands such as antibiotics and the properties of acidic, solubility, stability in $\mathrm{pH}$ range of 4-9 and preferential uptake by inflamed cells allows it to be chosen as ideal polymer. Bovine Serum Albumin (BSA) microspheres by phagocytosis are rapidly removed from the vascular system. On digestion of the albumin by lysosomal enzymes leads to release of free drug. Various drugs such as streptomycin, ofloxacin, clarithromycin and sodium cromoglicate when used with albumin microspheres, has significantly proven to be efficacious in lung targeting [13].

The microspheres intended as targeted delivery, injected via intravenous route enables to treat the deep lung disorders from the vascular side eliminating the need to traverse the mucus/surfactant and mucosal layers. At situations of compromised lung capacity and inhalation is not a viable option, use of injecting drug via intravenous route would be particularly helpful. It is evident that higher drug disposition in lungs and prolonged retention may translate into reduced doses, less frequent administration and lower bioavailability variability. Hence, the main purpose of this study was to prepare, develop and in vivo characterization of lung targeting efficiency to achieve high azithromycin concentration in lungs by way of Azithromycin Albumin Microsphere (AAM) as targeted drug delivery. The excellent tissue penetration enables azithromycin to get inappropriately deposit in various tissues such as liver and spleen apart from the infected lungs. Thus, the minimization of inappropriate azithromycin disposition and maintenance of higher azithromycin concentration in lungs can effectively combat the deeper lung tissue infections. 


\section{Methods}

\section{Materials}

Azithromycin was acquired as a gift sample from Karnataka Antibiotic Pharmaceutical Limited, Bengaluru, India. BSA fraction $\mathrm{V}$ was purchased from SD Fine-CHEM limited, Mumbai, India. The Tween 80, heavy liquid paraffin, nhexane, glutaraldehyde, petroleum ether, sodium bisulphite and Span 80 were obtained from Merck Specialties Pvt. Ltd, India. All the ingredients were of analytical grade.

\section{Experimental design}

The central composite design was used to optimize azithromycin loaded albumin microspheres (AAM) by altering albumin, glutaraldehyde and Span 80 concentrations. The independent variable factors effect on mean particle size of the microspheres along with encapsulation efficiency and $6^{\text {th }}$ hour in vitro drug release was investigated. The model contained eight factorial points, six axial points and six centre points with total 20 experiments. The mean value was set as 0 and, +1 and -1 was considered as higher and lower levels for each factor respectively. The selected factor constraints with their levels along with optimized levels are summarized in Tables 1 and 2 .

\section{Preparation of AAM intended for lung targeting}

Azithromycin microspheres were prepared using albumin, a biodegradable polymer by emulsion polymerization technique [14]. Initially, BSA was dissolved in distilled water (22.24 \%) and $0.5 \mathrm{~mL}$ of Tween 80 was added to the aqueous phase. Secondly, finely triturated $250 \mathrm{mg}$ of azithromycin was added into the aqueous phase with bath sonication (3 $\mathrm{min}$ ) for consistent dispersion. While stirring at $2500 \mathrm{rpm}, 1 \mathrm{~mL}$ of the above solution was slowly incorporated in to $30 \mathrm{~mL}$ of heavy liquid paraffin containing a lipophillic surfactant, Span 80. The mixture was homogenized for $10 \mathrm{~min}$ to form water/oil emulsion. To crosslink the albumin, the emulsion was homogenized by adding glutaraldehyde. Further, the emulsion was homogenized for $5 \mathrm{~min}$ with addition of $5 \mathrm{~mL} \mathrm{n}$-hexane for hardening the formed microspheres. The microspheres were then centrifuged at $1000 \mathrm{rpm}$ at room temperature for $1 \mathrm{~min}$ and washed with petroleum ether to remove the heavy liquid paraffin. To remove the residual glutaraldehyde, the

Table 1 Variable factors with their levels used for optimization of AAM

\begin{tabular}{lcllllll}
\hline Variable factors & \multicolumn{1}{l}{ Level } & & & & & $\begin{array}{l}\text { Optimized } \\
\text { level }\end{array}$ \\
\cline { 2 - 6 } & -1.41 & -1 & 0 & 1 & 1.41 & \\
\hline Albumin concentration (\%) & 16.59 & 20 & 25 & 30 & 33.41 & 22.24 \\
Glutaraldehyde volume (\%) & 0.16 & 0.3 & 0.50 & 0.7 & 0.84 & 0.58 \\
Span 80 volume (mL) & 0.20 & 0.4 & 0.70 & 1.0 & 1.20 & 1.0 \\
\hline
\end{tabular}

Table 2 Response factor constraints with expected and observed values for optimized AAM

\begin{tabular}{|c|c|c|c|c|}
\hline $\begin{array}{l}\text { Response } \\
\text { factors }\end{array}$ & Constraints & $\begin{array}{l}\text { Expected } \\
\text { value }\end{array}$ & $\begin{array}{l}\text { Observed } \\
\text { value }\end{array}$ & $\begin{array}{l}\text { Residual } \\
\text { value }\end{array}$ \\
\hline $\begin{array}{l}\text { Mean particle } \\
\text { size }(\mu \mathrm{m})\end{array}$ & Target of $8 \mu \mathrm{m}$ & 9.04 & 10.02 & 0.98 \\
\hline $\begin{array}{l}\text { Encapsulation } \\
\text { efficiency (\%) }\end{array}$ & In range & 81.4 & 80.00 & -1.4 \\
\hline $\begin{array}{l}6^{\text {th }} \text { hour in vitro } \\
\text { drug release }(\%)\end{array}$ & In range & 77.27 & 78.00 & 0.73 \\
\hline
\end{tabular}

microspheres were dispersed in $10 \mathrm{~mL}$ of $5 \% \mathrm{w} / \mathrm{v}$ sodium bisulphite solution and stirred on a magnetic stirrer for $5 \mathrm{~min}$. The microspheres were filtered through Whatmann filter paper with pore size of $0.45 \mu \mathrm{m}$ and again washed with $100 \mathrm{~mL}$ of water to completely remove residual glutaraldehyde. At room temperature, the microspheres were dried and were stored in a dessicator.

\section{Particle size measurement of the optimized AAM}

The particle size analysis [15] was carried out by photon correlation spectroscopy in Malvern Meta sizer, UK (HeNe laser beam at wavelength of $633 \mathrm{~nm}$ and $90^{\circ}$ scattering angle). Ten milligram of the preparation was dispersed in $0.1 \%$ of tween 80 containing $10 \mathrm{~mL}$ of water and was subjected to mean particle size determination. The mean particle size was averaged after three reading of the samples. The PCS software (Malvern Instruments Inc.) was used for processing of the data.

\section{Estimation of azithromycin}

Reverse phase high performance liquid chromatography (RP-HPLC) was used as analytical tool for quantitative estimation of azithromycin [16]. Stainless steel column $(25 \mathrm{~cm} \times$ $4.6 \mathrm{~mm}$ ) with end-capped octadecylsilyl amorphous organosilica polymer, $5 \mu \mathrm{m}$ (Waters Xterra) was used for analysis. Mobile phase in the ratio of 40:60 consisted of $0.18 \% \mathrm{w} / \mathrm{v}$ anhydrous disodium hydrogen phosphate solution $(\mathrm{pH}$ adjusted to 8.9 ) and a mixture of methanol (25 volumes) with acetonitrile (75 volumes), respectively. The injection volume was $50 \mu \mathrm{L}$ with flow rate of $1 \mathrm{~mL} / \mathrm{min}$. At $60{ }^{\circ} \mathrm{C}$ column temperature, UV detector was set at $210 \mathrm{~nm}$. The retention time of the drug peak was observed at $5.916 \mathrm{~min}$.

\section{Estimation of drug encapsulation efficiency of the optimized AAM}

The encapsulation efficiency was estimated by solvent extraction method [11]. Ten milligram of the microspheres was dispersed in $0.5 \mathrm{~mL}$ of methylene dichloride. Later, $4.5 \mathrm{~mL}$ of ethanol was added to precipitate the polymer. After stirring at $14,500 \mathrm{rpm}$ for $10 \mathrm{~min}$, the supernatant was separated and diluted with 10 times by PBS (pH 6.8, $50 \mathrm{mM}$ ). By previously mentioned RP- 
HPLC, the quantification of the drug was performed. Equations (1) and (2) were utilized to determine the drug encapsulation efficiency.

$$
\begin{aligned}
& \text { Drug loading }(\%)=\frac{D_{t}}{M_{t}} \times 100 \\
& \text { Encapsulation efficiency }(\%)=\frac{L_{a}}{L_{t}} \times 100
\end{aligned}
$$

$D_{t}$ : amount of encapsulated drug in microspheres; $M_{t}$ : microsphere quantity; $L_{a}$ : actual drug content and $L_{t}$ : theoretical drug content.

\section{X-ray diffraction (XRD) analysis}

The XRD analysis of azithromycin powder, BSA and AAM formulation (Pre and post stability studies at refrigeration and accelerated conditions) was performed using Philips X'Pert Pro, Netherlands at $40 \mathrm{KV}$ voltages and applied $30 \mathrm{~mA}$ of current (nickel-filtered $\mathrm{CuK} \alpha$ radiation). The sample was scanned over a $2 \theta$ range of $10-800$ with an interval of 0.020 at the rate of $20 / \mathrm{min}$.

In vitro study and curve fitting analysis of the optimized AAM Azithromycin release from AAM was estimated using Franz diffusion cells. The cell consisted of a dialysis membrane with MW cut-off of 12,000-14,000 Da (Himedia Laboratories Pvt. Ltd, Mumbai, India). This membrane acted as a barrier between donor and acceptor compartment. Hundred milligram of the microspheres dispersed in $1 \mathrm{~mL}$ of phosphate saline buffer (PBS) was placed in the donor compartment. The PBS was prepared by dissolving $0.2 \mathrm{~g}$ of potassium chloride, $1.44 \mathrm{~g}$ of disodium hydrogen phosphate, and $0.24 \mathrm{~g}$ of dihydrogen potassium phosphate in $800 \mathrm{~mL}$ of distilled water. The $\mathrm{pH}$ was maintained at 7.4 and the volume was made upto $1000 \mathrm{~mL}$ [17]. At $37 \pm 0.5{ }^{\circ} \mathrm{C}, 200 \mathrm{~mL}$ of PBS was placed in the acceptor compartment and stirred on a magnetic stirrer at $200 \mathrm{rpm}$. At specified time, $1 \mathrm{~mL}$ of the solution was pipetted out from the acceptor compartment and was replaced with the same volume of PBS. The drug content was determined utilizing the formerly mentioned RP-HPLC method. After three runs, the data was utilized to determine release kinetics.

Using Sigma plot, the release kinetics of the optimized AAM was fitted to various models such as first order model (3), Higuchi square root model (4), Baker and Lonsdale (5), Koresmeyer-Peppas (6) and Hixson and Crowell cube root model (7) to study the release of drug from the microspheres.

$$
\begin{aligned}
& \log \left(100-Q_{t}\right)=\log Q_{0}-\frac{K_{t}}{2.303} \\
& Q_{t}=k_{H} \sqrt{t}
\end{aligned}
$$

$$
\begin{aligned}
& \frac{Q_{t}}{Q_{\infty}}=1-\frac{6}{\pi^{2}} \exp \left(\frac{-\pi^{2} \times D t}{r^{2}}\right) \\
& Q_{t}=Q_{0}+a\left(\frac{t}{r^{2}}\right)^{n}+b\left(\frac{t}{r^{2}}\right)^{2 n} \\
& \sqrt[3]{Q_{0}}-\sqrt[3]{Q_{t}}=\mathrm{k}_{\mathrm{HC}} t
\end{aligned}
$$

$Q_{t}$ is the total amount of drug release after $t$ time (\%); $\mathrm{Q}_{0}$ is the initial amount of drug (\%); $K$ is the first order release rate constant $\left(\mathrm{h}^{-1}\right) ; \mathrm{k}_{\mathrm{H}}$ is the rate constant obtained according to the Higuchi equation $\left(\% \mathrm{~h}^{-1 / 2}\right) ; \mathrm{Q}_{\infty}$ is the percent release at infinite time; $D$ is the diffusion coefficient in the polymer in $\mathrm{cm}^{2} / s ; r$ is the radius of the sphere in $\mathrm{cm} ; n$ and $2 n$ are the release exponent for Fickian diffusion and case II transport, respectively; $a$ and $b$ are constants related to the drug and the structural and geometric properties of the microparticles; and $\mathrm{k}_{\mathrm{HC}}$ is the rate constant obtained according to the Hixon and Crowell equation $\left(\% \mathrm{~h}^{-1}\right)[18-20]$.

\section{Stability study of the optimized AAM}

The stability study was conducted as per ICH Q1AR guideline, intended to test the stability for new substances and product. The optimized preparation was stored at $5 \pm 3{ }^{\circ} \mathrm{C}$ for twelve months and at $25 \pm 2{ }^{\circ} \mathrm{C}$ and $60 \pm 5 \% \mathrm{RH}$ for a period of six months. The required volume of microsphere dispersion was stored in closed glass bottles and sealed tightly. At regular intervals, the sample was subjected for determination of encapsulation efficiency, mean particle size distribution and for any physical changes. The test was carried at 3 month intervals for a period of 12 months for long term storage condition under refrigeration and at $0,2,4$ and 6 months for accelerated condition at room temperature. To confirm the stability of the drug in the formulation, the samples were also subjected to XRD analysis.

\section{In vivo pharmacokinetic studies in albino mice}

The animal experiments were carried out in accordance to the protocol approved by the Institutional Animal Ethics Committee formed under CPCSEA guidelines. Prior to the study, thirty six adult male and female, Swiss Albino mice, weighing $20 \pm 3 \mathrm{~g}$ was kept starving for $12 \mathrm{~h}$ with free access to water. AAM microspheres were dispersed in saline with $1 \%$ of Tween 80 and vortexed for $5 \mathrm{~s}$. The control group received azithromycin (in saline) solution containing a dose of $50 \mathrm{\mu g} \mathrm{g}^{-1}$ injected intravenously via tail vein, while the AAM group was injected with equivalent content of azithromycin in AAM. 


\section{Blood or organ isolation and extraction}

At specified intervals $(0.5 \mathrm{~h}, 1 \mathrm{~h}, 3 \mathrm{~h}, 6 \mathrm{~h}, 8 \mathrm{~h}$ and $12 \mathrm{~h})$, the blood samples were collected from the ocular artery directly from each mouse after eye ball removal and placed into heparinized test tubes. By centrifugation (4000 g) for $15 \mathrm{~min}$, the plasma was immediately separated. The animals were then sacrificed by cervical dislocation. The plasma and tissue samples of targeted organs such as lung, liver and spleen were isolated and stored at $-20{ }^{\circ} \mathrm{C}$ for $24 \mathrm{~h}$. To determine the targeted release, the azithromycin concentration in each organ was determined by subjecting $1 \mathrm{~g}$ (after removal of surface water) of the tissue sample through extraction process. The normal saline $\left(0.1 \mathrm{mg} \mathrm{mL}^{-1}\right)$ was added to the isolated organs and homogenized. To precipitate protein, $2 \mathrm{~mol} \mathrm{~L}^{-1}$ perchloric acid $(100 \mu \mathrm{L})$ was added to the plasma sample and homogenized tissues. Subsequently, $300 \mu \mathrm{L}$ of plasma or homogenized tissues suspension was added to $450 \mu \mathrm{L}$ methanol. The mixture was vortexed for $60 \mathrm{~s}$ and then centrifuged at 10,000 g for $5 \mathrm{~min}$ [17]. The supernatant was collected and filtered through a $0.22 \mu \mathrm{m}$ pore size Phenomenex filter. The azithromycin concentration in the processed samples was quantitatively analyzed by above mentioned RP-HPLC method.

\section{Pharmacokinetic parameters}

Change in azithromycin concentration with time was monitored in blood, lung, liver and spleen. Based on the analysis of parameters and model, the two compartment model could best describe the in vivo pharmacokinetics of microspheres in blood. The azithromycin, area under the curve $\left(\mathrm{AUC}_{0-\infty}\right)$ was determined from the beginning of the intravenous injection $\left(t_{0}\right)$ to the last observation $\left(\mathrm{t}_{\text {last }}\right)$ by linear trapezoidal rule with extrapolation to infinite time. Additionally, azithromycin half life ( $\mathrm{t}_{1 / 2} \alpha$ and $\beta)$, distribution rate constants $\left(K_{21}, K_{10}\right.$ and $\left.K_{12}\right)$, clearance $(\mathrm{CL})$ and apparent volume of distribution at steady state $\left(\mathrm{V}_{\mathrm{SS}}\right)$ were also calculated. The Kinetica 5.0 $\mathrm{PK} / \mathrm{PD}$ analysis software was also utilized for the calculation of pharmacokinetic parameters.

\section{Lung targeting characteristics and histopathological studies}

The lung targeting efficiency of AAM was evaluated by using intake rate $\left(r_{e}\right)$, targeting efficacy $\left(t_{e}\right)$ and peak concentration ratio $\left(C_{e}\right)$ [21]. At the end of the study (12 h post sample administration), the animals were subjected to experimenting process by excess anesthesia. To examine the tissue tolerability of the formulation specified organs (lungs, liver and spleen) were washed with cold saline. Later, the organs were pressed between filter pads and weighed. Using $10 \%$ formalin, the tissues were fixed and stained with hematoxylin and eosin. Under light microscopy with $200 \times$ magnification, the tissue samples were examined for any cytoarchitecture changes.

\section{Statistical analysis}

Statistical analysis was carried out by using Student's $t$ test with a $P$ value less than 0.05 was considered as statistically significant.

\section{Results and discussion Preparation of AAM}

Compared to other macrolides, azithromycin enhances extended spectrum and potency especially against pneumonia [5]. The biocompatibility, low toxicity, non antigenicity and physicochemical property of the BSA influenced to select it as an ideal polymer in this study. The preparation of

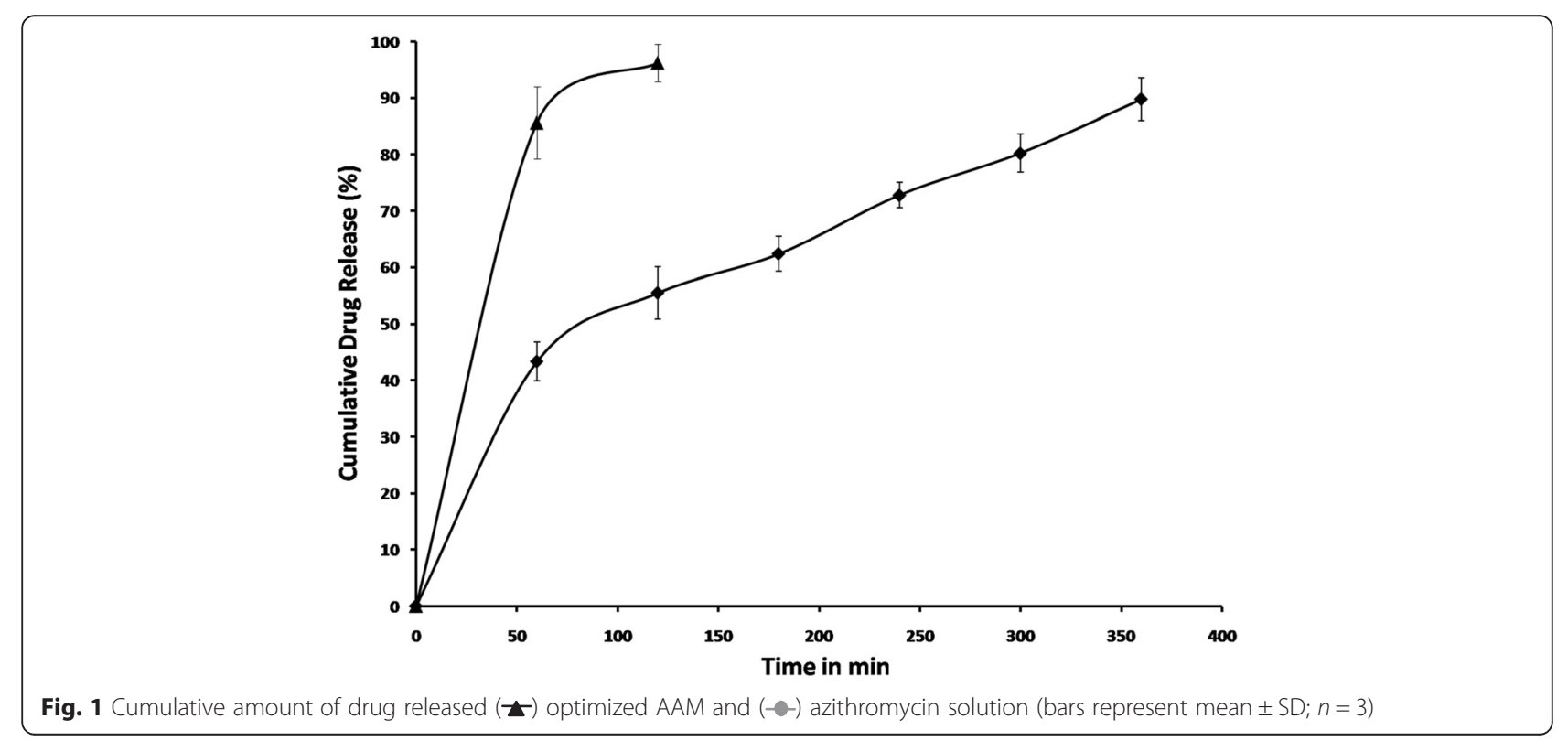




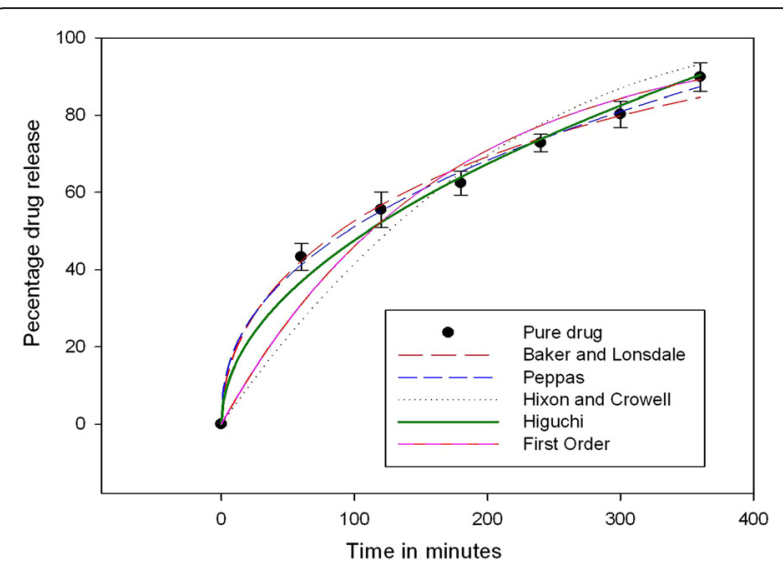

Fig. 2 In vitro release profile of the optimized AAM-curve fitting models (bars represent mean $\pm \mathrm{SD} ; n=3$ )

albumin microsphere involved suspending an aqueous solution of albumin in an external non-polar phase. The nuclei formation due to the micronized azithromycin induces small droplet formation during emulsification resulting in smaller microsphere until steady state droplet size distribution. Glutaraldehyde a five-carbon dialdehyde, chemically cross links with albumin lysines. The glutaraldehyde as a fixative enhances covalent stabilization of the albumin producing stable and biocompatible microspheres. However, the residual glutaraldehyde could be toxic and was removed by bisulphate wash. The carbonyl group pi bond of glutaraldehyde was subjected to nucleophilic addition of bisulphate resulting in organic sulphite (water soluble sodium salt), which was further removed by water washing. Many earlier studies [22, 23] have successfully used emulsion polymerization for albumin microsphere preparations. This method was found to be advantageous, as the microspheres from the high molecular weight polymers are usually shaped at a faster rate and at low temperature.

\section{Mean particle size and drug encapsulation efficiency}

Albumin microspheres in the range of $1-100 \mu \mathrm{m}$ influence its biodistribution characteristics. Particle size was found to be a significant factor to distinguish between soluble carrier and particulate systems. The particle size being an important parameter for drug targeting with microspheres, as the size helps in discharge of drug in controlled manner and uptake of drugs into the tissues. In this study, the particle size ranged from 3.9-19.8 $\mu \mathrm{m}$ and the mean particle size of the optimized AAM was $10.02 \mu \mathrm{m}$. Various other studies [17, 22, 24] have reported similar particle size for albumin microspheres. Following intravenous administration, $7-15 \mu \mathrm{m}$ particle size range of microspheres gets deposited in the lungs by mechanical entrapment [10]. To support this hypothesis, Kutscher et al. [25] proved that $10 \mu \mathrm{m}$ sized microspheres were uniformly distributed throughout the lung

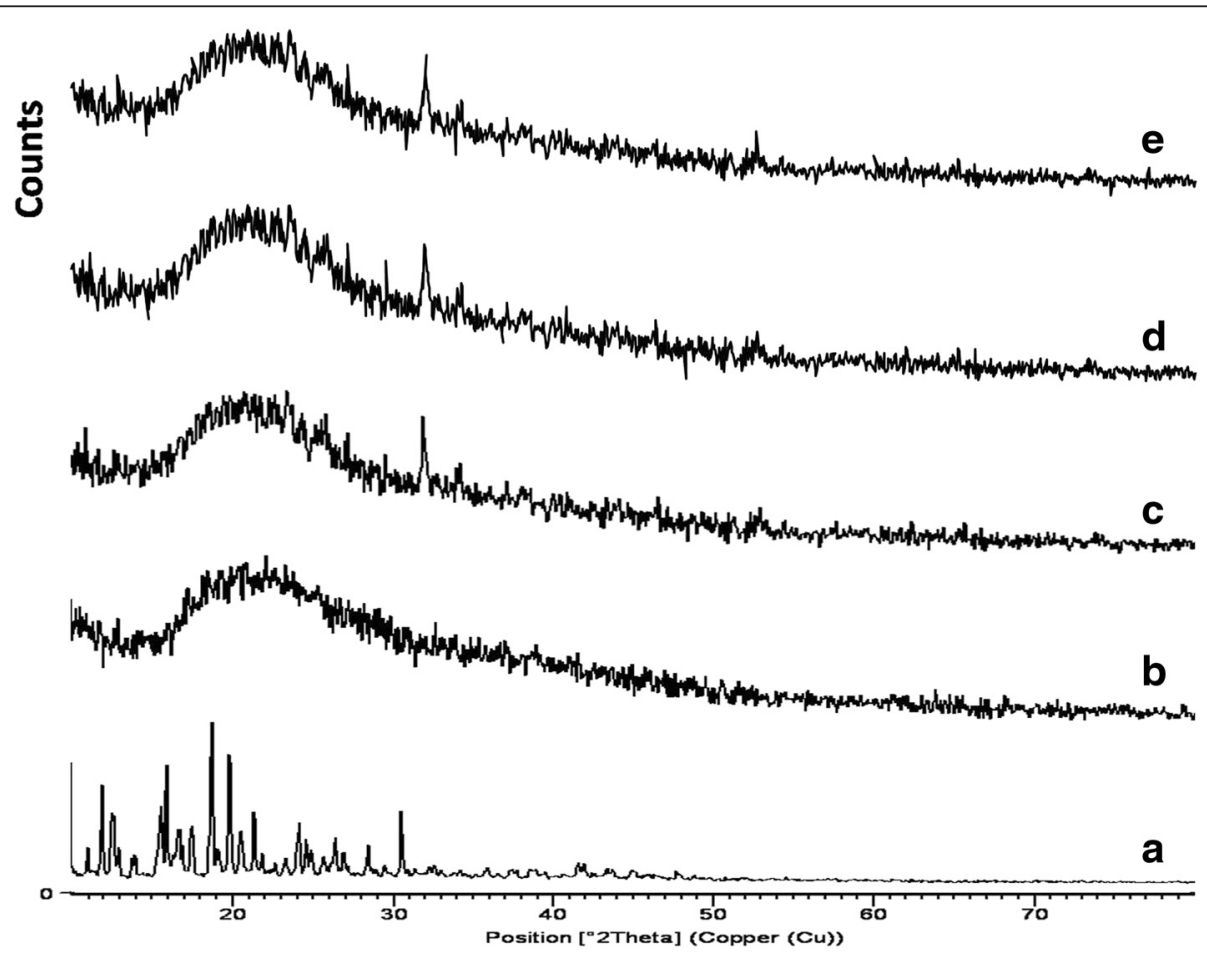

Fig. 3 XRD of (a) azithromycin; (b) BSA; (c) optimized AAM before stability study; (d) optimized AAM after refrigeration $\left(5 \pm 3{ }^{\circ} \mathrm{C}\right)$ for 12 months; (e) optimized AAM after acceleration $\left(25 \pm 2^{\circ} \mathrm{C}\right)$ for 6 months 
Table 3 Stability test observations of the optimized AAM at refrigeration for long term storage condition

\begin{tabular}{|c|c|c|c|c|c|c|c|c|c|c|c|c|c|c|c|}
\hline \multirow{2}{*}{$\frac{\text { Storage }}{5 \pm 3^{\circ} \mathrm{C}}$} & \multicolumn{5}{|c|}{ Encapsulation efficiency (\%) } & \multicolumn{5}{|c|}{ Mean particle size $(\mu \mathrm{m})$} & \multicolumn{5}{|c|}{ Physical change } \\
\hline & \multicolumn{5}{|c|}{ Months } & \multicolumn{5}{|c|}{ Months } & \multicolumn{5}{|c|}{ Months } \\
\hline & 0 & 3 & 6 & 9 & 12 & 0 & 3 & 6 & 9 & 12 & 0 & 3 & 6 & 9 & 12 \\
\hline & 68.1 & 67.5 & 66.8 & 66.0 & 65.0 & 10.02 & 09.98 & 10.01 & 10.02 & 10.02 & - & - & - & - & - \\
\hline
\end{tabular}

-: No physical change

capillaries to that of $3 \mu \mathrm{m}$ sized microspheres, which usually pass through the lungs.

The injected microspheres primarily get lodged in alveolar capillaries that have diameters considerably less than those of the microspheres and thus, the concept of mechanical entrapment offers a unique opportunity for passive targeting of microspheres to lungs. Since there is a possibility of larger microspheres occluding larger capillaries leading to blockage of small downstream vessels may result in augmentation of potential toxic effect. To resolve this issue and avoid embolism due to injected microspheres, the USP has stated that " $>90 \%$ of microspheres must have a size between 10-90 $\mu \mathrm{m}$ and no microspheres may be larger than $150 \mu \mathrm{m}$ ". A study by Glenny et al. [26] reported that the blood flow in rat lungs was not significantly affected by $15 \mu \mathrm{m}$ particle size of the microspheres and neither emboli nor tissue infarction was observed. The same study states that these microspheres will occlude only a small fraction of capillaries (0.5-0.7 \%) and significantly do not alter local vascular resistance. Within the capillaries, red blood cells can continue to flow past lodged microspheres.

In fact, the lung at rest only uses approximately $30 \%$ of its capacity and is therefore able to recruit other capillaries to avoid massive increases in the arterial pressure when blockages do occur. Additionally, the lung utilizes variety of ways such as recruiting unused vessels and use of arteriovenous shunts to improve the blood circulation in the pulmonary capillaries. Microspheres with $1-3 \mu \mathrm{m}$ particle size passes through the lung and will be removed by reticuloendothelial system and, usually accumulate in liver and spleen, excrete through the feces or sequestration by macrophages in other organ systems [25].

The maximum encapsulation efficiency of $82.3 \%$ was observed in this study. The high encapsulation efficiency may also have contributed to low partition coefficient of azithromycin. Studies done by Bozdag et al. [24] and Jones et al. [27] stated that the albumin microspheres can be sustained and the encapsulation efficiency can be increased by escalating glutaraldehyde volume. The swelling, encapsulation efficiency and drug release profile can be controlled by cross linking density.

\section{In vitro study and curve fitting analysis}

AAM in vitro release study (Fig. 1) showed a minimum of $40.34 \%$ and a maximum of $94.63 \%$ of azithromycin release at the end of $1^{\text {st }}$ hour and $6^{\text {th }}$ hour, respectively. AAM showed biphasic in vitro drug release viz, an initial burst followed by sustained release at the end. The initial burst was due to the dispersed drug close to the microsphere surface and additionally, high encapsulation also contributes to this effect. The diffusion of dispersed drug in the polymeric matrix and BSA erosion would lead to the sustained release of the microspheres. Initial burst effect was required to provide the loading dose of the drug to combat the high bacterial load which usually seen during the initial phase of pneumonia.

The release pattern of the optimized formulation on sigma plot has been represented in Fig. 2. The regression coefficient of Korsmeyer-Peppas model $\left(R^{2}=0.9962\right)$ was significant. The Korsmeyer-Peppas model illustrates the drug release mechanism from polymeric devices. To describe the drug release process, the $n$-value can be obtained by fitting data into Korsemeyer Peppas model. The $n$-value was found to be 0.41 , indicating Fickian diffusion type of release. Due to dispersion of the azithromycin in polymeric matrix, the dissolution may not be rate limiting step, but the diffusion of the drug through polymeric matrix considered to be the slowest step for drug release. A study [14] showed similar behavior for albumin microspheres.

\section{XRD analysis}

XRD of the pure azithromycin, albumin and AAM (Pre and post stability studies at refrigeration and accelerated conditions) are shown in Fig. 3. XRD spectral characteristic of the azithromycin pure drug shows many diffraction peaks, indicating the crystallinity of the drug. In contrast,

Table 4 Stability test observations of the optimized AAM at room temperature for accelerated condition

\begin{tabular}{|c|c|c|c|c|c|c|c|c|c|c|c|c|}
\hline \multirow{2}{*}{$\frac{\text { Storage }}{25 \pm 2^{0} \mathrm{C}}$} & \multicolumn{4}{|c|}{ Encapsulation efficiency (\%) } & \multicolumn{4}{|c|}{ Mean particle size $(\mu \mathrm{m})$} & \multicolumn{4}{|c|}{ Physical change } \\
\hline & \multicolumn{4}{|c|}{ Months } & \multicolumn{4}{|c|}{ Months } & \multicolumn{4}{|c|}{ Months } \\
\hline & 0 & 2 & 4 & 6 & 0 & 2 & 4 & 6 & 0 & 2 & 4 & 6 \\
\hline & 68.1 & 67.8 & 67.3 & 66.9 & 10.02 & 10.02 & 10.01 & 10.01 & - & - & - & - \\
\hline
\end{tabular}

-: No physical change 
Table 5 Pharmacokinetic parameters after intravenous injection of AAM and azithromycin solution (control) in albino mice

\begin{tabular}{lll}
\hline Pharmacokinetic Parameters & AAM & Azithromycin solution \\
\hline AUC $\left._{0-\infty}(\mu \mathrm{g} \mathrm{h} \mathrm{mL})^{-1}\right)$ & 32.73 & 88.70 \\
$\mathrm{t}_{1 / 2}(\mathrm{a})(\mathrm{h})$ & 0.950 & 0.522 \\
$\mathrm{t}_{1 / 2}(\beta)(\mathrm{h})$ & 11.38 & 10.32 \\
$\mathrm{~K}_{21}\left(\mathrm{~h}^{-1}\right)$ & 0.400 & 0.940 \\
$\mathrm{~K}_{10}\left(\mathrm{~h}^{-1}\right)$ & 0.111 & 0.940 \\
$\mathrm{~K}_{12}\left(\mathrm{~h}^{-1}\right)$ & 1.88 & 0.360 \\
$\mathrm{CL}\left(\mathrm{h}^{-1}\right)$ & 0.102 & 0.061 \\
$\mathrm{~V}_{\mathrm{ss}}(\mathrm{L})$ & 9.49 & 1.26 \\
$\mathrm{C}_{0}\left(\mu \mathrm{g} \mathrm{mL} \mathrm{L}^{-1}\right)$ & 6 & 11 \\
\hline
\end{tabular}

Data are represented as means \pm SD $(n=3)$

the diffraction peaks was significantly reduced in AAM. XRD of BSA shows one peak, which indicates non crystallinity. The AAM formulation showed decreased crystallinity of azithromycin, which was similar to that of BSA indicating the incorporation of azithromycin in the polymer.

\section{Stability study}

The stability test observations of the optimized AAM at room temperature and refrigeration conditions are depicted in Tables 3 and 4. On storage, no major deviations were observed in the macroscopic characteristics. There were no changes in mean particle size of the optimized formulations stored at $25{ }^{\circ} \mathrm{C}$. On storage, the extent of microsphere sedimentation was not prominent, on manual agitation they were redispersed easily. Even though, there was slight decrease in the encapsulation efficiency (3.1\%), but was within the acceptable range. Thus, the optimized formula proved to be stable on long term and accelerated storage conditions as well.

\section{In vivo pharmacokinetic studies}

Based on the analysis of parameters and model, the two compartment model could best describe the in vivo pharmacokinetics of microspheres in blood. The pharmacokinetic parameters are illustrated in Table 5. The decisive parameters for the penetration into biological fluids and tissues are the drug molecular weight, lipophilicity and protein binding [13]. Compared to control, AAM altered in vivo azithromycin distribution and the half-life of azithromycin released from AAM intravenous injection $\left(\mathrm{t}_{1 / 2}(\alpha)=0.950 \mathrm{~h}, \mathrm{t}_{1 / 2}(\beta)=11.38 \mathrm{~h}\right)$ were prominently higher than the intravenous injection of azithromycin solution $\left(\mathrm{t}_{1 / 2}(\alpha)=0.522 \mathrm{~h}, \mathrm{t}_{1 / 2}(\beta)=10.32 \mathrm{~h}\right)$. This data proves the sustained release efficacy of AAM. Azithromycin concentration in mice lungs $\left(40.62 \mu \mathrm{g} \mathrm{g} \mathrm{g}^{-1}\right.$, $30 \mathrm{~min}$ ) of AAM was appreciably higher than other tissues and plasma. In comparison with control, azithromycin concentration in lungs was $30.15 \mu \mathrm{g} \mathrm{g} \mathrm{g}^{-1}$ after 30 min. A clinical study [28] has shown that the initial high upfront release of azithromycin from the microspheres helps in achieving higher azithromycin concentration required to act against the early bacterial burden at the infection site in lungs.

After intravenous injection of AAM and azithromycin solution preparations, the distribution of azithromycin with time was estimated in lung, liver, spleen $\left(\mu \mathrm{g} \mathrm{mL} \mathrm{L}^{-1}\right)$ and blood $\left(\mu \mathrm{g} \mathrm{g}^{-1}\right)$. Azithromycin concentration in blood and other organs was considered as $100 \%$. The targeting parameters are shown in Table 6. The semilogarithmic plot showing azithromycin distribution in mice after intravenous injection of AAM and azithromycin solution (control) are shown in Fig. 4a and b, respectively. Azithromycin tissue distribution was found to be higher than plasma concentration in all time points. Azithromycin concentration in lungs considered to be a vital factor in achieving an effective clinical treatment. The capillary blockade (as a function of particle size) resulting in mechanical filtration leads to accumulation of microspheres in lung.

AAM showed the highest value of AUC $(929.94 \mu \mathrm{g} \mathrm{h} \mathrm{mL}$ ${ }^{-1}$ ) and re (8.88) for lung, and the difference was statistically significant $(p=0.0011)$. The AAM targeting efficacy $\left(t_{\mathrm{e}}\right)$ of lung increased by a factor of 40.15 (compared with spleen) and 14.10 (compared with liver). The targeting ratio of AAM increased by a factor of 46.39 (compared to spleen) and 16.21 (compared to liver). Additionally, compared with control the ratio of peak concentration in lung $\left(C_{e}\right)$ increased by a factor of 8.94. Literatures state that PAEs are

Table 6 Lung-targeting parameters after intravenous administration of AAM and azithromycin solution (control) in albino mice

\begin{tabular}{|c|c|c|c|c|c|c|c|c|c|}
\hline \multirow[t]{2}{*}{ Parameters } & \multicolumn{2}{|l|}{$A \cup C^{a}$} & \multirow[t]{2}{*}{$r_{e}$} & \multicolumn{2}{|l|}{$t_{e}$} & \multirow{2}{*}{$\begin{array}{l}\left(t_{e}\right)_{\text {AAM }} / \\
\left(t_{e}\right)_{\text {Control }}\end{array}$} & \multicolumn{2}{|l|}{$C_{p}^{a}$} & \multirow[t]{2}{*}{$C_{e}$} \\
\hline & AAM & Control & & AAM & Control & & AAM & Control & \\
\hline Blood & 32.73 & 88.69 & 0.369 & 28.42 & 1.18 & 24.06 & 5.60 & 10.80 & 0.519 \\
\hline Liver & 65.97 & 120.45 & 0.547 & 14.10 & 0.870 & 16.21 & 7.75 & 12.00 & 0.646 \\
\hline Spleen & 23.16 & 121.01 & 0.191 & 40.15 & 0.866 & 46.39 & 2.94 & 18.27 & 0.160 \\
\hline Lung & 929.94 & 104.75 & 8.88 & 1.00 & 1.00 & 1.00 & 93.65 & 10.47 & 8.94 \\
\hline
\end{tabular}

$\mathrm{r}_{\mathrm{e}}=(\mathrm{AUC})_{\mathrm{AAM}} /(\mathrm{AUC})_{\text {Control }}$

$t_{e}=(A \cup C)_{\text {lung targeted }} /(A \cup C)_{\text {untargeted }}$

$C_{p}$ : peak concentration $\left(\mu \mathrm{g} \mathrm{m}^{-1}\right.$ or $\left.\mu \mathrm{g} \mathrm{g}^{-1}\right) C_{\mathrm{e}}=\left(C_{\mathrm{p}}\right)_{\text {AAM }} /\left(C_{\mathrm{p}}\right)_{\text {Contro }}$

anit of AUC: $\mu \mathrm{g} \mathrm{h} \mathrm{mL}^{-1}$ or $\mu \mathrm{g} \mathrm{h} \mathrm{g}^{-1}$ 

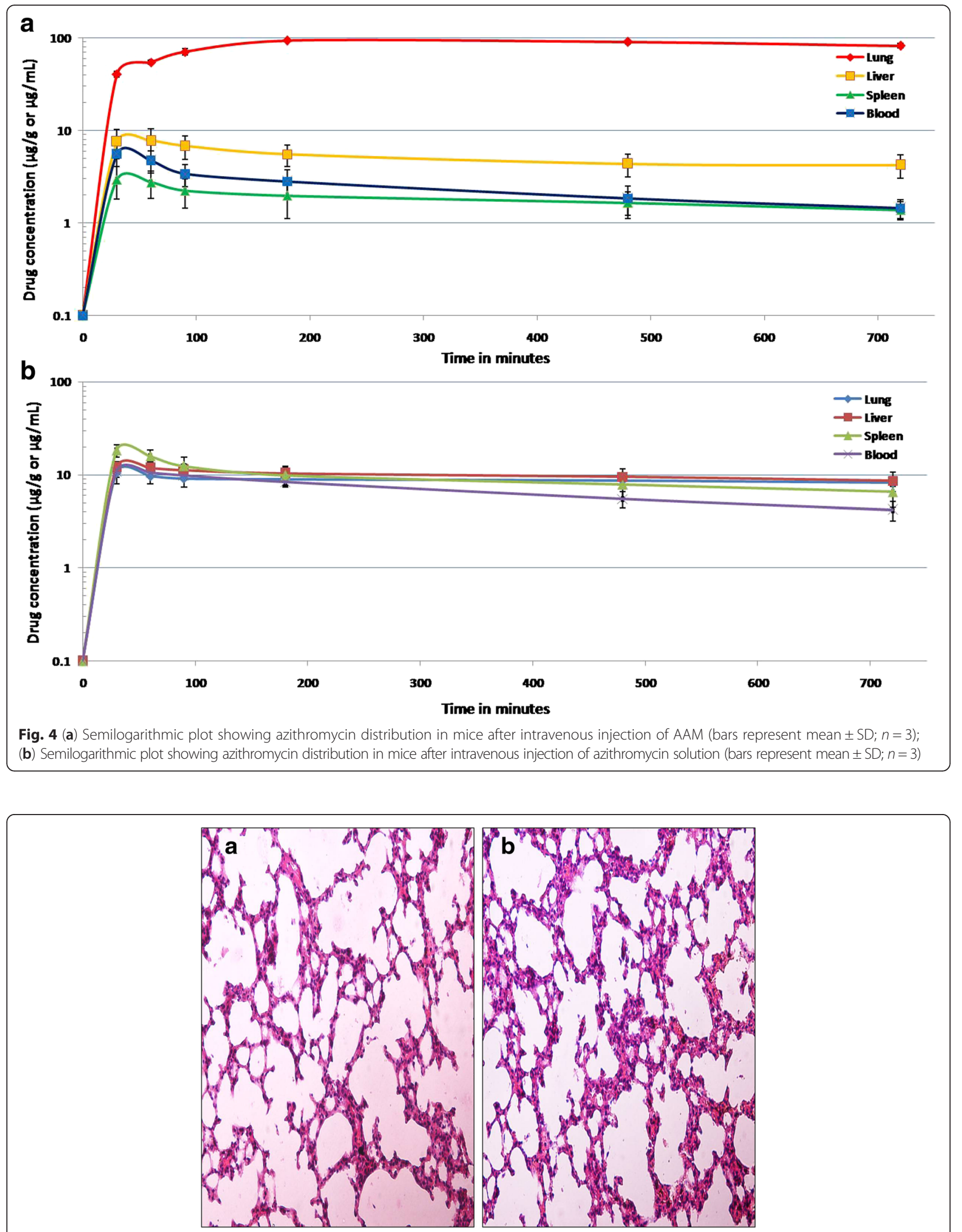

Fig. 5 (a) Cytoarchitecture of albino mice lung (azithromycin solution); (b) Cytoarchitecture of albino mice lung (AAM) 
usually investigated at ten times the MIC and in this study the azithromycin concentration was all time maintained above MIC. Among macrolides, the longer retain time $(t>$ $\mathrm{MIC}$ ) at the target site and strongest PAE up to $2.3-4.7 \mathrm{~h}$ of azithromycin results in relatively short treatment period [9].

Albumin microsphere improves circulatory half-lives of the drug by inhibiting drug uptake by reticuloendothelial system [14]. In this study, the albumin microsphere certainly has further influenced the accumulation of azithromycin particularly in lungs. The presence of specific albumin binding protein in alveolar epithelial cells further increases affinity to albumin leading to higher azithromycin concentration especially in lungs [29]. The protection of microspheres from opsonization and decreased urinary clearance of BSA $(67 \mathrm{kDa})$ considered to be also a beneficial effect [30]. High azithromycin loading in lung tissues by AAM compared to control confirms the alteration in biodistribution of the azithromycin thus, the lung targeting characteristic of AAM was evident.

The tissue tolerability considered to be a major concern as in microsphere based targeted system due to accumulation of the drug and excipients in the targeted organs. The histopathology of the mice lungs (Fig. 5a and b) did not show any degenerative changes in the AAM formulation compared to control group. This proves the safety and biocompatibility of the AAM as a parenteral formulation for lung targeting.

\section{Conclusions}

Currently a single dose extended release azithromycin formulation has been found to be the only FDA approved antibiotic for the treatment of pneumonia. This study successfully formulated azithromycin incorporation into albumin microspheres. The particle size, encapsulation efficiency, in vitro study, release kinetics, XRD and stability study showed the suitability of the microspheres for lung targeting. In comparison with control, AAM showed better azithromycin concentration in lungs, higher AUC, the ratio of peak concentration $\left(C_{e}\right)$ and intake rate $\left(r_{e}\right)$. The favorable in vivo pharmacokinetics, lung targeting efficacy and histopathology proved applicability of the microspheres as targeted drug delivery to lungs.

\section{Competing interests}

The authors declare that they have no competing interests.

\section{Authors' contributions}

BR conceived the study, designed, carried out experiments and drafted the manuscript. SN assisted in design, analysis, interpretation of the data and manuscript plagiarism check. UGK coordinated the experiments, involved in XRD, stability studies and drafting the manuscript. PRB and RS participated in the design of the study, interpretation of the data, performed the statistical analysis and revised the manuscript. All authors read and approved the final manuscript.

\section{Acknowledgements}

We are thankful to Prof. Basavaraj Ramnal, Secretary and Dr. Ramesh K, Director, Karnataka College of Pharmacy, Bengaluru, Karnataka, India, for valuable contribution to make this research work possible. We also thank Mr. Lokesh Prasad, DTL, Bengaluru, Karnataka, India, for proof reading the article.

\section{Author details}

'Department of Pharmaceutics, Karnataka College of Pharmacy, \#33/2, Tirumenahalli, Hegde Nagar Main Road, Bengaluru, Karnataka 560064, India. ${ }^{2}$ Department of Pharmaceutical Sciences, College of Clinical Pharmacy, King Faisal University, Al-Ahsa 31982, Saudi Arabia. ${ }^{3}$ Department of Pharmaceutical Technology, Karnataka College of Pharmacy, \#33/2, Tirumenahalli, Hegde Nagar Main Road, Bengaluru 560064, Karnataka, India.

Received: 9 November 2015 Accepted: 27 April 2016

Published online: 05 May 2016

\section{References}

1. Giordano RJ, Edwards JK, Tuder RM, Arap W, Pasqualini R. Combinatorial ligand-directed lung targeting. Proc Am Thorac Soc. 2009;6:411-5.

2. Hittinger $M$ et al. Preclinical safety and efficacy models for pulmonary drug delivery of antimicrobials with focus on in vitro models. Adv Drug Deliv Rev. 2014. http://dx.doi.org/10.1016/j.addr.2014.10.011

3. Zhang Z, Zhu Y, Yang X, Li C. Preparation of azithromycin microcapsules by a layer-by-layer self-assembly approach and release behaviors of azithromycin. Colloids Surf A Physicochem Eng Asp. 2010;362:135-9.

4. Blasi F, Aliberti S, Tarsia P. Clinical applications of azithromycin microspheres in respiratory tract infections. Int J Nanomed. 2007;2:551-9.

5. Zhang $Y$, Wang $X$, Lin X, Liu X, Tian B, Tang X. High azithromycin loading powders for inhalation and their in vivo evaluation in rats. Int J Pharm. 2010;395:205-14.

6. Harrison TS, Keam SJ. Azithromycin extended release-a review of its use in the treatment of acute bacterial sinusitis and community-acquired pneumonia in the US. Drugs. 2007;67:773-92.

7. Amrol D. Single-dose azithromycin microsphere formulation: a novel delivery system for antibiotics. Int J Nanomed. 2007;2:9-12.

8. Lucchi M, Damle B, Fang A, De Caprariis PJ, Mussi A. Pharmacokinetics of azithromycin in serum, bronchial washings, alveolar macrophages and lung tissue following a single oral dose of extended or immediate release formulations of azithromycin. J Antimicrob Chemother. 2008;61:884-91.

9. Levison ME. Pharmacodynamics of antimicrobial drugs. Infect Dis Clin N Am. 2004;18:451-65.

10. Ozkan Y, Dikmen N, Isimer A, Gunhan O, Aboul-Enein HY. Clarithromycin targeting to lung: characterization, size distribution and in vivo evaluation of the human serum albumin microspheres. II Farmaco. 2000;55:303-7.

11. Li X, Chang S, Du G, Li Y, Gong J. Encapsulation of azithromycin into polymeric microspheres by reduced pressure-solvent evaporation method. Int J Pharm. 2012:433:79-88.

12. Elsadek B, Kratz F. Impact of albumin on drug delivery-New applications on the horizon. J Contr Rel. 2012;157:4-28.

13. Saroglou M, Ismailos G, Tryfon S, Liapakis I, Papalois A, Bouros D. Penetration of azithromycin in experimental pleural empyema fluid. Eur J Pharmacol. 2010;626:271-5.

14. Thakkar H, Sharma RK, Mishra AK, Chuttani K, Murthy RR. Albumin microspheres as carriers for the antiarthritic drug celecoxib. AAPS PharmSciTech. 2005;6:E65-73.

15. Zeng XM, Martin GP, Marriott C. Preparation and in vitro evaluation of tetrandrine-entrapped albumin microspheres as an inhaled drug delivery system. Eur J Pharm Sci. 1995;3:87-93.

16. Ghari T, Kobarfard F, Mortazavi SA. Development of a simple RP-HPLC-UV method for determination of azithromycin in bulk and pharmaceutical dosage forms as an alternative to the USP method. Iranian J Pharm Res. 2013;12:57-63.

17. Harsha S, Chandramouli R, Rani S. Ofloxacin targeting to lungs by way of microspheres. Int J Pharm. 2009;380:127-32.

18. Dillen K, Vandervoort J, Mooter GV, Ludwig A. Evaluation of ciprofloxacinloaded eudragit ${ }^{\circledast}$ RS100 or RL100/PLGA nanoparticles. Int J Pharm. 2006;314:72-82

19. Gibaud S, Al Awwadi NJ, Ducki C, Astier A. Poly(-caprolactone) and eudragit microparticles containing fludracortisones acetate. Int J Pharm. 2004;269:491-508.

20. Huang J, Wigent RJ, Bentzley CM, Schwartz JB. Nifedipine solid dispersion in microparticles of ammonio methacrylate copolymer and ethylcellulose 
binary blend for controlled drug delivery effect of drug loading on release kinetics. Int J Pharm. 2006;319:44-54.

21. Lu B, Zhang JQ, Yang H. Lung-targeting microspheres of carboplatin. Int J Pharm. 2003;265:1-11.

22. Gulsu A, Ayhan H, Ayhan F. Preparation and characterization of ketoprofen loaded albumin microspheres. Turk J Biochem. 2012;37:120-8.

23. Mathew ST, Devi SG, Sandhya KV. Formulation and evaluation of ketorolac tromethamine-loaded albumin microspheres for potential intramuscular administration. AAPS PharmSciTech. 2007;8:E1-9.

24. Bozdag S, Çalis S, Kas HS, Ercan MT, Peksoy I. In vitro evaluation and intraarticular administration of biodegradable microspheres containing naproxen sodium. J Microencapsul. 2001;18:443-56.

25. Kutscher HL, Chao P, Deshmukh M, Singh Y, Hu P, Joseph LB, et al.

Threshold size for optimal passive pulmonary targeting and retention of rigid microparticles in rats. J Contr Rel. 2010;144:31-7.

26. Glenny RW, Bernard S, Lamm WJ. Hemodynamic effects of 15-mm-diameter microspheres on the rat pulmonary circulation. J Appl Physiol. 2000;89:499-504.

27. Jones C, Burton MA, Gray BN. Albumin microspheres as vehicles for the sustained and controlled release of doxorubicin. J Pharm Pharmacol. 1989; 41:813-6.

28. Blumer JL. Evolution of a new drug formulation: the rationale for high-dose, short-course therapy with azithromycin. Int J Antimicrob Agents. 2005;26:S143-7.

29. Todoroff J, Vanbever R. Fate of nanomedicines in the lungs. Curr Opin Colloid Interface Sci. 2011;16:246-54

30. Yamashita F, Hashida M. Pharmacokinetic considerations for targeted drug delivery. Adv Drug Deliv Rev. 2013;65:139-47.

\section{Submit your next manuscript to BioMed Central} and we will help you at every step:

- We accept pre-submission inquiries

- Our selector tool helps you to find the most relevant journal

- We provide round the clock customer support

- Convenient online submission

- Thorough peer review

- Inclusion in PubMed and all major indexing services

- Maximum visibility for your research

Submit your manuscript at www.biomedcentral.com/submit 